\title{
A cross-sectional study of determinants of indoor environmental exposures in households with and without chronic exposure to biomass fuel smoke
}

Suzanne L Pollard ${ }^{1,2}$, D’Ann L Williams³, Patrick N Breysse ${ }^{3}$, Patrick A Baron³, Laura M Grajeda², Robert H Gilman ${ }^{2,4}$, J Jaime Miranda ${ }^{4,5}$, William Checkley ${ }^{1,2,4^{*}}$ and CRONICAS Cohort Study Group

\begin{abstract}
Background: Burning biomass fuels indoors for cooking is associated with high concentrations of particulate matter (PM) and carbon monoxide (CO). More efficient biomass-burning stoves and chimneys for ventilation have been proposed as solutions to reduce indoor pollution. We sought to quantify indoor PM and CO exposures in urban and rural households and determine factors associated with higher exposures. A secondary objective was to identify chronic vs. acute changes in cardiopulmonary biomarkers associated with exposure to biomass smoke.

Methods: We conducted a census survey followed by a cross-sectional study of indoor environmental exposures and cardiopulmonary biomarkers in the main household cook in Puno, Peru. We measured 24-hour indoor PM and CO concentrations in 86 households. We also measured $\mathrm{PM}_{2.5}$ and $\mathrm{PM}_{10}$ concentrations gravimetrically for 24 hours in urban households and during cook times in rural households, and generated a calibration equation using $\mathrm{PM}_{2.5}$ measurements.

Results: In a census of 4903 households, $93 \%$ vs. $16 \%$ of rural vs. urban households used an open-fire stove; $22 \%$ of rural households had a homemade chimney; and $<3 \%$ of rural households participated in a national program encouraging installation of a chimney. Median 24-hour indoor PM 2.5 and CO concentrations were $130 \mathrm{vs.} 22 \mathrm{\mu g} / \mathrm{m}^{3}$ and $5.8 \mathrm{vs} .0 .4$ ppm (all $\mathrm{p}<0.001$ ) in rural vs. urban households. Having a chimney did not significantly reduce median concentrations in 24-hour indoor $\mathrm{PM}_{2.5}$ (119vs. $137 \mu \mathrm{g} / \mathrm{m}^{3} ; \mathrm{p}=0.40$ ) or $\mathrm{CO}$ (4.6 vs. $7.2 \mathrm{ppm} ; \mathrm{p}=0.23$ ) among rural households with and without chimneys. Having a chimney did not significantly reduce median cook-time $\mathrm{PM}_{2.5}\left(360 \mathrm{vs} .298 \mathrm{\mu g} / \mathrm{m}^{3}, \mathrm{p}=0.45\right)$ or cook-time CO concentrations (15.2 vs. 9.4 ppm, $p=0.23$ ). Having a thatched roof ( $p=0.007)$ and hours spent cooking ( $\mathrm{p}=0.02$ ) were associated with higher 24-hour average PM concentrations. Rural participants had higher median exhaled CO (10 vs. 6 ppm; $p=0.01)$ and exhaled carboxyhemoglobin (1.6\% vs. 1.0\%; $p=0.04)$ than urban participants.
\end{abstract}

Conclusions: Indoor air concentrations associated with biomass smoke were six-fold greater in rural vs. urban households. Having a homemade chimney did not reduce environmental exposures significantly. Measures of exhaled CO provide useful cardiopulmonary biomarkers for chronic exposure to biomass smoke.

Keywords: Biomass smoke, Biomass fuel, Cookstoves, Biomarkers, Exhaled carbon monoxide, Environmental exposure

\footnotetext{
* Correspondence: wcheckl1@jhmi.edu

'Division of Pulmonary and Critical Care, School of Medicine, Johns Hopkins University, 1800 Orleans Ave, Suite 9121, Baltimore, MD, USA

2Program in Global Disease Epidemiology and Control, Department of International Health, Johns Hopkins University, Bloomberg School of Public Health, Baltimore, MD, USA

Full list of author information is available at the end of the article
} 


\section{Background}

More than half the world population uses solid fuels indoors for cooking and home heating. Incomplete combustion of these materials results in the production of hazardous air pollutants that affect respiratory health $[1,2]$. The World Health Organization has identified indoor combustion of biomass solid fuels as the fourth leading risk factor for disease burden worldwide [3]. In 2010, indoor air pollution caused an estimated 4 million premature deaths and is the most important environmental risk factor globally and in poor regions of the world [4]. Biomass smoke exposure is highest among women and children, as these groups generally spend more time in the home and in areas designated for cooking.

Particulate matter (PM), especially particles $<2.5 \mu \mathrm{m}$ in diameter $\left(\mathrm{PM}_{2.5}\right)$, is a key component of biomass fuel smoke. Exposure to PM from biomass combustion has important effects on the development of respiratory diseases. In particular, exposure to biomass smoke is associated with acute respiratory infections in children, lung cancer, chronic obstructive pulmonary disease, asthma, and cardiovascular disease, among others [5-17]. Of these, COPD is most highly correlated with air pollution exposure [18]. Carbon monoxide $(\mathrm{CO})$ is also produced by the incomplete combustion of carbon-containing biomass fuels. $\mathrm{CO}$ results in tissue hypoxia due to its higher affinity to hemoglobin as compared to oxygen; thus, carboxyhemoglobin and oxygen saturation levels in the blood are key indicators in determining the effects of acute $\mathrm{CO}$ exposure. $\mathrm{CO}$ also acts through direct CO-mediated damage at the cellular level [19]. Acute exposure to high levels of CO can cause serious neuropsychiatric damage and can be lethal. In addition, chronic exposure to $\mathrm{CO}$ can have important health consequences, especially in those with underlying conditions such as anemia, asthma, and coronary artery disease, which impair tissue oxygenation [20]. Given the high burden of disease attributable to biomass fuel use, there is considerable interest in the design of interventions, such as chimney stoves, for reducing exposures to indoor biomass smoke. In addition, there is interest in introducing cleaner fuel types, such as liquid propane gas (LPG), in households that currently use biomass. However, there is little information to date on the effectiveness of these measures in reducing exposures to indoor pollutants. Furthermore, while previous studies have quantified the concentrations of indoor PM and $\mathrm{CO}$ resulting from the combustion of solid fuels [21-26], few have attempted to identify biomarkers of such exposures.

Our primary objective was to quantify indoor PM and $\mathrm{CO}$ concentrations in an urban city center and its surrounding rural communities. Urban dwellers almost exclusively use LPG for cooking, whereas rural populations primarily use biomass fuels for their domestic energy needs. Furthermore, we sought to evaluate how effective locally made, home-built chimneys are in reducing exposures to indoor pollutants. A secondary objective was to identify chronic vs. acute changes in cardiopulmonary markers associated with exposure to biomass fuel smoke. Specifically, we evaluated exhaled nitric oxide (eNO), exhaled carbon monoxide (eCO), carboxyhemoglobin measured from exhaled breath (eHbCO), oxygen saturation $\left(\mathrm{SpO}_{2}\right)$, carboxyhemoglobin measured from pulse cooximetry (SpHBCO), and heart rate (HR) to evaluate their potential use as clinical biomarkers for biomass smoke exposure.

\section{Methods}

\section{Study setting}

The study population was comprised of adults $\geq 18$ years of age living in Puno, Peru, and surrounding rural communities, at 3825 meters above sea level. Urban participants were selected from Puno city, commonly work in commerce or education, and use clean fuels, such as LPG, for cooking. Rural participants consist of native subsistence farmers who cook almost exclusively with traditional, open-fire stoves and biomass fuels (i.e., wood, animal dung, and crop residue). The majority of rural kitchens are made of adobe and do not have chimneys. In the vast majority of traditional households, the kitchen is built as a separate building next to the main living area, and the primary cook of the household is almost always female. Cooking is generally performed twice per day, in the early morning and early evening, although the frequency and timing of cooking is somewhat variable. It is not uncommon for women to cook with biomass materials in the morning, then use a gas stove to heat up leftover food for the evening meal. The kitchen windows are small and are usually kept closed, especially in the winter, due to low temperatures at high altitudes. Participants who could read provided written informed consent. Participants who could not read provided verbal consent. The study was approved by the Institutional Review Board of Johns Hopkins University in Baltimore, USA, and A.B. PRISMA in Lima, Peru.

\section{Study design}

We first conducted a door-to-door census of 2,248 urban households in the city of Puno and 1,845 rural households in surrounding communities between July 2010 and September 2010 in specific districts in the department of Puno. We asked questions regarding the location of the kitchen in reference to the main living area, whether the kitchen had a chimney, the type of stove used, and whether or not the household had participated in JUNTOS, a national program providing improved cookstoves to rural residents in Peru [27].

Based on our community census, we selected a random sample of households in three of the following groups (target 30 per group): urban households that predominantly 
cook with clean fuels (i.e., LPG), rural households that predominantly cook with biomass fuels and have a chimney, and rural households that predominantly cook with biomass fuels but do not have a chimney. Our sample was recruited between January 2011 and November 2011. In total, 104 participants completed a biomass exposure questionnaire. We conducted direct-reading nephelometric PM measurements in 86 homes (27 urban, 28 rural with chimney, 31 rural without chimney). Some rural homes $(n=5)$ cooked only with LPG during the sampling period; however, these homes used biomass fuels on a regular basis to cook. We chose to include these homes in primary analyses because our main goal was to characterize environmental exposures in rural households of Puno, whether or not they cooked with biomass fuels. None of the urban homes cooked with biomass during the sampling period. We also carried out direct-reading $\mathrm{CO}$ measurements in 85 homes, gravimetric $\mathrm{PM}_{2.5}$ measurements in 73 homes, and measured cardiopulmonary outcomes in 99 participants of which $76 \%(n=75)$ completed all measurements.

\section{Measurement of indoor environmental exposures}

We measured indoor PM concentrations for a 24-hour period in one-minute intervals in all homes, both urban and rural, using the pDR-1000 in passive mode (Thermo Fisher Scientific, Waltham, MA). Particle monitors were placed $1.5-2.0$ meters off the ground and $0.5-1.0$ meters away from the stove. Temperature and humidity were also recorded every minute alongside PM measurements using the HOBO U10 data logger (Onset Corporation, Bourne MA); we adjusted nephelometric PM data for humidity according to previously described methods (28). pDRs were zeroed before each use according to manufacturer instructions.

To quantify coarse and fine fractions of PM, gravimetric measurements of $\mathrm{PM}_{2.5}$ and $\mathrm{PM}_{10}$ concentrations were obtained concurrently using the DataRAM pDR-1000 converted for active sampling with size-selective inlets and fitted with the PCXR4 universal sampling pump (SKC Inc., Eighty Four, PA) set to a flow rate of $4 \mathrm{~L} / \mathrm{min}$ and 1.2 $\mathrm{L} / \mathrm{min}$ for $\mathrm{PM}_{2.5}$ and $\mathrm{PM}_{10}$ respectively. We also used data from gravimetric samples to develop a calibration curve and convert nephelometric PM values to gravimetricequivalent $\mathrm{PM}_{2.5}$ concentrations. In urban households, gravimetric measurements were conducted for 24-hour periods. In rural households, we conducted gravimetric measurements during morning and evening cook times and when necessary changed the filter using pre-loaded cassettes in order to avoid overloading the filters. Pump flow rates were pre- and post-calibrated in the study office before and after sampling in the field. We excluded filters for which the flow rate change exceeded $25 \%$ from all analyses. All filters were weighed pre- and post-sampling in a temperature- and humidity-controlled weighing room at the NIEHS Exposure Assessment Core facility, Johns Hopkins Bloomberg School of Public Health.

We carried out 24-hour direct-reading measurements of indoor $\mathrm{CO}$ using a direct-reading instrument in urban and rural homes. We used the EasyLog USB CO Monitor (Lascar Electronics, Erie, PA), which was left in the kitchen during the 24-hour period. Monitors were placed 1.5 - 2.0 meters off the ground and $0.5-1.0$ meters from the stove in order to approximate the cook's location.

\section{Measurement of outdoor environmental exposures}

We measured outdoor ambient PM concentrations for a 24-hour period in one-minute intervals twice per month (one weekday and one weekend) from March 2011 through October 2011, using the pDR-1000 in passive mode (Thermo Fisher Scientific, Waltham, MA). Particle monitors were placed on the roof of the study office in the city of Puno. Temperature and humidity were also recorded every minute alongside PM measurements using the HOBO U10 data-logger (Onset Corporation, Bourne MA). We adjusted nephelometric PM data for humidity according to previously described methods (28). pDRs were zeroed before each use according to manufacturer instructions.

\section{Quantification of household biomass smoke exposure with a questionnaire}

We administered a questionnaire to the main cook of all households. We collected information regarding demographics, cooking frequency, time spent cooking on a typical day, stove and fuel type history and typical use, whether participants used an improved stove, and smoking history. We defined biomass burn-years as a measure of cumulative exposure to biomass smoke. One biomass burn-year was equivalent to one hour of biomass use per day multiplied by one year of cooking with biomass, or 365 hours cooking with biomass.

\section{Characterization of household construction}

Two or more trained observers assessed aspects of household characteristics including stove type, room volume, the materials of the floor, walls, and roof, the number and

Table 1 Census results comparing rural and urban households in Puno

\begin{tabular}{|c|c|c|c|}
\hline Census survey & Rural (\%) & Urban (\%) & p-value \\
\hline$N=4093$ & $\mathrm{n}=1845$ & $n=2248$ & \\
\hline $\begin{array}{l}\text { Is the kitchen connected } \\
\text { to the main house? }\end{array}$ & $225(12 \%)$ & $954(42 \%)$ & $<0.001$ \\
\hline Does the kitchen have a chimney? & $406(22 \%)$ & $219(10 \%)$ & $<0.001$ \\
\hline $\begin{array}{l}\text { Do you have an open-fire } \\
\text { stove design? }\end{array}$ & 1733 (94\%) & $362(16 \%)$ & $<0.001$ \\
\hline $\begin{array}{l}\text { Have you participated in the national } \\
\text { program for improved cookstoves? }\end{array}$ & $45(2 \%)$ & $9(<1 \%)$ & $<0.001$ \\
\hline
\end{tabular}


area of windows and doors, the state of windows and doors (open or closed), the location of the kitchen and its proximity to living space, and the presence of a chimney.

\section{Collection of time activity information}

In rural households, we visited households during morning and evening cook times. Two or more trained observers were present for the duration of each cook time, and we directly observed the type of stove and fuel being used, the size of windows and doors, and the number of open windows and doors.

\section{Assessment of cardiopulmonary biomarkers}

We visited each household and conducted measurements of eCO, eNO, eHbCO, and $\mathrm{SpO}_{2}$ levels on the main cook of the household. The objective of this analysis was to identify chronic vs. acute changes in these clinical biomarkers with exposure to high concentrations of PM and $\mathrm{CO}$ produced by the burning of biomass fuels. We chose eNO as a non-invasive measure of airways inflammation. Given that combustion of biomass results in high exposures to $\mathrm{CO}$, we also explored the utility of eCO and $\mathrm{SpO}_{2}$ as biomarkers of exposure. Lastly, we chose these biomarkers because they are simple to measure, which is important because of the logistical challenges involved in biomass fuel studies.

We carried out these measurements once in urban households and up to four times in rural households: immediately before and after each of two cooking sessions conducted within 24 hours of each other. eCO and eHbCO levels were collected using the Micro CO Meter (Micro Direct, Lewiston, ME). Measurements of eNO were taken using the NIOXMINO Airway Inflammation Monitor (Aerocrine, Solna, Sweden), and levels of $\mathrm{SpO}_{2}$ and $\mathrm{SpCO}$ in the blood were assessed using the $\operatorname{Rad} 57 \mathrm{c}$ carboxyoximeter (Masimo Corp, Irvine, CA).

\section{Biostatistical methods}

We used linear regression methods to generate a calibration equation using gravimetric and humidity-corrected passive nephelometric measurements [28] representing 24-hour averages in urban households and cook time averages in rural households. We log-transformed both gravimetric and nephelometric measurements in generating the equation.

We conducted basic comparisons of census data and demographic and household characteristics using Fisher's exact test and the Kruskal-Wallis test, where appropriate. We compared environmental exposures (24-hour average $\mathrm{PM}$, 24-hour CO, cook time PM, cook time $\mathrm{CO}$ ) and physiological outcomes (eNO, eCO, eHbCO, $\mathrm{SpCO}, \mathrm{SpO}_{2}$ ) using the Mann Whitney U test, and we compared physiological outcomes before and after cooking using the Wilcoxon Signed-Rank test. Approximately 30\% of eNO levels after cooking were missing because of difficulties using the machine in cold temperatures. In our comparison of outcomes in urban and rural participants, we used the averages of all outcome measurements conducted on rural participants (one measurement before and one after cooking for each of two cook sessions, for a total of four measurements). In our comparison of outcomes before and after cooking in rural participants, we used the average of measurements before cooking (up to two per participant) and average of measurements after cooking (also up to two per participant). Measurements were conducted only once on urban participants.

We used multivariable linear regression to evaluate the association between PM concentrations (24-hour average and cook time) and kitchen and cooking factors in rural houses only. This analysis excluded urban homes and rural homes that used LPG for cooking. We used generalized estimating equations to account for correlation between morning and afternoon measurements within each household. The final model was selected using a quasi-likelihood information criterion (QIC) approach. We log-transformed both 24-hour average and cook time PM concentrations because they were right skewed. We excluded rural households that cooked with gas in this analysis because they were few in number and because we were most interested in how household factors relate to PM generated from biomass fuel smoke.

We conducted our analyses in R (www.r-project.org) and STATA 11 (Stata Corp., College Station, Texas).

\section{Results}

\section{Characteristics of the study population}

Responses to the household census regarding kitchen and stove characteristics are summarized in Table 1. A small proportion of rural households reported having a chimney, and an even smaller percentage of respondents had participated in the national improved cookstove program that provides a cash incentive for households who build an improved cookstove [27]. In Table 2, we summarize demographic and household characteristics in participating urban and rural households. Nearly all main cooks across groups were female, and cooks in rural homes with chimneys were slightly younger than other groups. A large majority of rural cooks used a traditional cookstove at every meal, whereas no urban cooks did so. However, some urban participants (9.4\%) used traditional stoves on occasion. Lifetime cumulative exposure to biomass was significantly higher in rural participants as compared to urban participants. A small proportion of households had improved cookstoves in our study population. Only one participant in our study smoked on a daily basis, and overall lifetime cumulative exposure to smoking was negligible. 
Table 2 Demographic and household characteristics in study participants living in urban households, and rural households with and without chimneys

\begin{tabular}{|c|c|c|c|c|c|}
\hline \multirow[b]{2}{*}{ Characteristic } & \multicolumn{4}{|c|}{ Mean (SD) or \% } & \multirow[b]{2}{*}{ P-value } \\
\hline & $\begin{array}{l}\text { Total } \\
(n=104)\end{array}$ & $\begin{array}{l}\text { Urban } \\
(n=32)\end{array}$ & $\begin{array}{l}\text { Rural-chimney } \\
(n=34)\end{array}$ & $\begin{array}{l}\text { Rural-no chimney } \\
(n=38)\end{array}$ & \\
\hline \multicolumn{6}{|l|}{ Demographics } \\
\hline Age (years) & 48 & 51 & 43 & 52 & 0.03 \\
\hline Sex (\% female) & 98.1 & 100 & 100 & 94.7 & 0.33 \\
\hline \multicolumn{6}{|l|}{ Cooking history } \\
\hline Years cooking & 32 & 31 & 29 & 36 & 0.17 \\
\hline Years cooking with traditional stove & 24 & 5 & 28 & 35 & $<0.001$ \\
\hline Biomass burn-years ${ }^{*}$ & 116 & 16 & 84 & 226 & $<0.001$ \\
\hline \multicolumn{6}{|l|}{ Stove and fuel use } \\
\hline Hours spent cooking per day & 3.9 & 3.0 & 2.9 & 5.5 & 0.17 \\
\hline Cooking frequency, \% who cook every day & $96.1 \%$ & $90.6 \%$ & $97.1 \%$ & $100 \%$ & 0.07 \\
\hline Cooking frequency per day, n (\%) & & & & & $<0.001$ \\
\hline 1 & $9(8.7)$ & $6(18.8)$ & $1(2.8)$ & $2(5.6)$ & \\
\hline 2 & $69(66.4)$ & $7(21.9)$ & $31(86.1)$ & $31(86.1)$ & \\
\hline 3 & $26(25.0)$ & $19(59.4)$ & $3(8.8)$ & $4(10.5)$ & \\
\hline$\%$ cooking every meal with a traditional cookstove & 55.8 & 0 & 79.4 & 81.6 & $<0.001$ \\
\hline$\%$ using a traditional cookstove (any frequency) & 70.2 & 9.4 & 100 & 94.7 & $<0.001$ \\
\hline \multicolumn{6}{|l|}{ Biomass fuel sources (participants could select $\geq 1$ ), n (\%) } \\
\hline Wood & $72(69.2)$ & $8(25.0)$ & $31(91.2)$ & $33(86.8)$ & $<0.001$ \\
\hline Dung & $75(72.1)$ & $8(25.0)$ & $31(91.2)$ & $36(94.7)$ & $<0.001$ \\
\hline Agricultural materials & $36(35.0)$ & $0(0)$ & $15(44.1)$ & $21(56.8)$ & $<0.001$ \\
\hline \multicolumn{6}{|l|}{ Improved cookstoves } \\
\hline Has improved cookstoves, n (\%) & $5(4.8)$ & $1(3.1)$ & $3(8.3)$ & $1(2.8)$ & 0.62 \\
\hline Uses improved stove regularly & 1 & 0 & 1 & 0 & \\
\hline Improved cookstove via JUNTOS, n (\%) & $0(0)$ & & & & \\
\hline \multicolumn{6}{|l|}{ Smoking history } \\
\hline Current daily smokers, n (\%) & $1(0.9 \%)$ & $1(2.9 \%)$ & 0 & 0 & \\
\hline Cumulative pack-years among all participants & 0.08 & 0.22 & 0 & 0.02 & 0.34 \\
\hline \multicolumn{6}{|l|}{ Kitchen characteristics } \\
\hline$\%$ with kitchen separate from main living area & 78.6 & 29.0 & 100 & 100 & $<0.001$ \\
\hline Volume of kitchen (cubic meters) & 24.0 & 30.5 & 22.8 & 19.6 & 0.06 \\
\hline$\%$ with a dirt floor & 66.0 & 12.9 & 85.3 & 92.1 & $<0.001$ \\
\hline$\%$ with adobe walls & 66.0 & 9.7 & 97.1 & 84.2 & $<0.001$ \\
\hline Roof material, n (\%) & & & & & $<0.001$ \\
\hline Concrete & $22(21.4)$ & $21(67.7)$ & $0(0.0)$ & $1(2.6)$ & \\
\hline Corrugated iron & $44(42.7)$ & $7(22.6)$ & $22(64.7)$ & 15 (39.5) & \\
\hline Thatch & $29(28.2)$ & $0(0.0)$ & $11(32.4)$ & $18(47.4)$ & \\
\hline Other & $8(7.8)$ & $3(9.7)$ & $1(2.9)$ & $4(10.5)$ & \\
\hline
\end{tabular}

\section{Calibration equation of nephelometric to gravimetric}

\section{$\mathrm{PM}_{2.5}$ concentrations}

Gravimetric $\mathrm{PM}_{2.5}$ and nephelometric PM concentrations were linearly related in the log scale (Figure 1).
Although nephelometric PM concentrations overestimated gravimetric $\mathrm{PM}_{2.5}$ concentrations on average by $50 \%$, the relationship was consistent and could be predicted with the following equation: Gravimetric $\mathrm{PM}_{2.5}=$ 


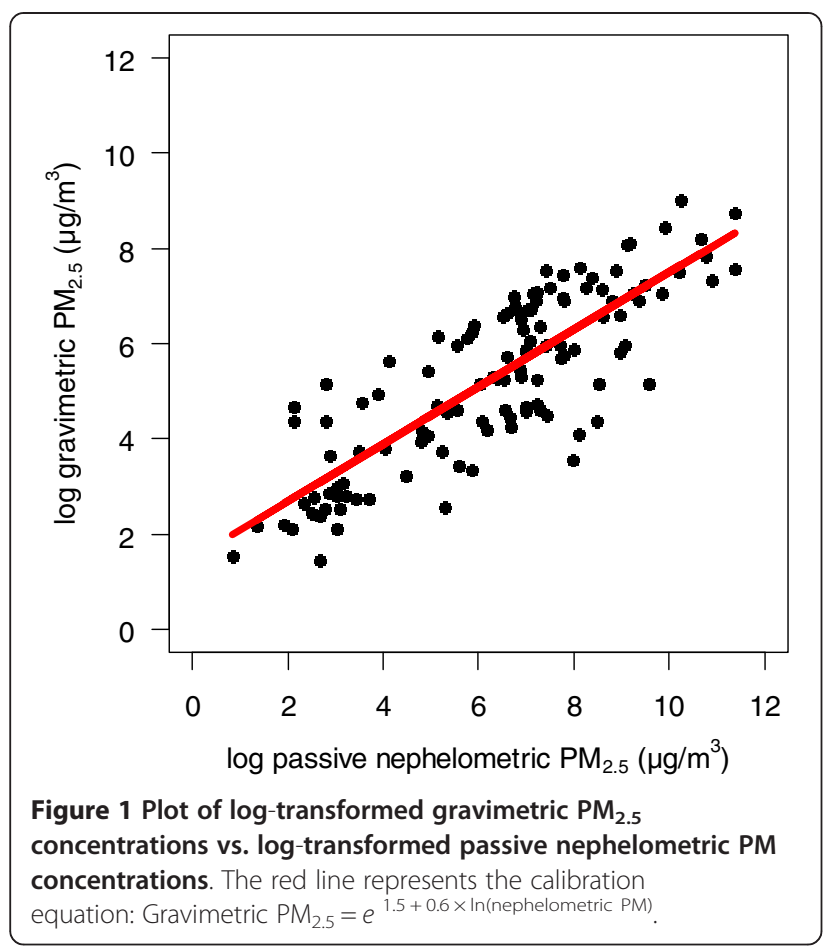

$e^{1.5+0.6 \times \ln (\text { nephelometric } \mathrm{PM})}$ This equation was used to convert nephelometric $\mathrm{PM}$ concentrations to $\mathrm{PM}_{2.5}$ equivalent concentrations.

\section{Household environmental exposures}

Median, average, and maximum hourly PM concentrations were substantially lower in urban houses vs. rural houses throughout the course of a 24-hour day (Figure 2). In rural homes with and without chimneys, PM concentrations peaked at approximately six in the morning and six in the evening, corresponding with observed practices regarding cook times during the day. We observed smaller, less distinct maximum concentrations in urban households, although concentrations tended to be higher overall in the daytime hours and peaked slightly at seven in the morning, one in the afternoon, and seven in the evening. We found little difference in exposure between rural homes with and without chimneys $(\mathrm{p}=0.40)$.

Median average hourly $\mathrm{CO}$ concentrations were also substantially lower in urban houses vs. rural houses (Figure 3). Maximum CO concentrations in rural households and trends mimic those of PM concentrations; however, $\mathrm{CO}$ concentrations decreased from their maxima more slowly than PM concentrations over time (i.e., CO concentrations remained persistently higher for a longer period than did PM concentrations before returning to zero). There is a slight increase in urban household $\mathrm{CO}$ concentrations at approximately one in the afternoon.

Median 24-hour average $\mathrm{PM}_{2.5}$ equivalent concentrations were 22 vs. $130 \mu \mathrm{g} / \mathrm{m}^{3}(\mathrm{p}<0.001)$ and $\mathrm{CO}$ concentrations were $0.4 \mathrm{ppm}$ vs. $5.8 \mathrm{ppm}$ for urban vs. rural houses $(\mathrm{p}<0.001)$, respectively. Median 24-hour PM and CO concentrations were $119 \mu \mathrm{g} / \mathrm{m}^{3}$ and $137 \mu \mathrm{g} / \mathrm{m}^{3} \quad(\mathrm{p}=0.40)$ and $4.6 \mathrm{ppm}$ and $7.2 \mathrm{ppm}(\mathrm{p}=0.30)$ for rural houses with and without chimneys, respectively. Median cook time PM and CO concentrations were $298 \mu \mathrm{g} / \mathrm{m}^{3}$ vs. $360 \mu \mathrm{g} / \mathrm{m}^{3}$ ( $\mathrm{p}=0.45$ ), and 9.4 ppm vs. $15.2 \mathrm{ppm}(\mathrm{p}=0.23)$ in rural houses with and without chimneys, respectively. The Pearson correlation coefficient between 24-hour average PM and CO concentrations for urban households was 0.07 (95\% CI 0.33 to 0.44 ), and for rural households was 0.67 (95\% CI 0.49 to 0.79 ). Pearson correlation coefficients for rural houses with chimneys and rural houses without chimneys were 0.54 (95\% CI 0.21 to 0.76 ) and 0.79 (95\% CI 0.52 to 0.92$)$, respectively.
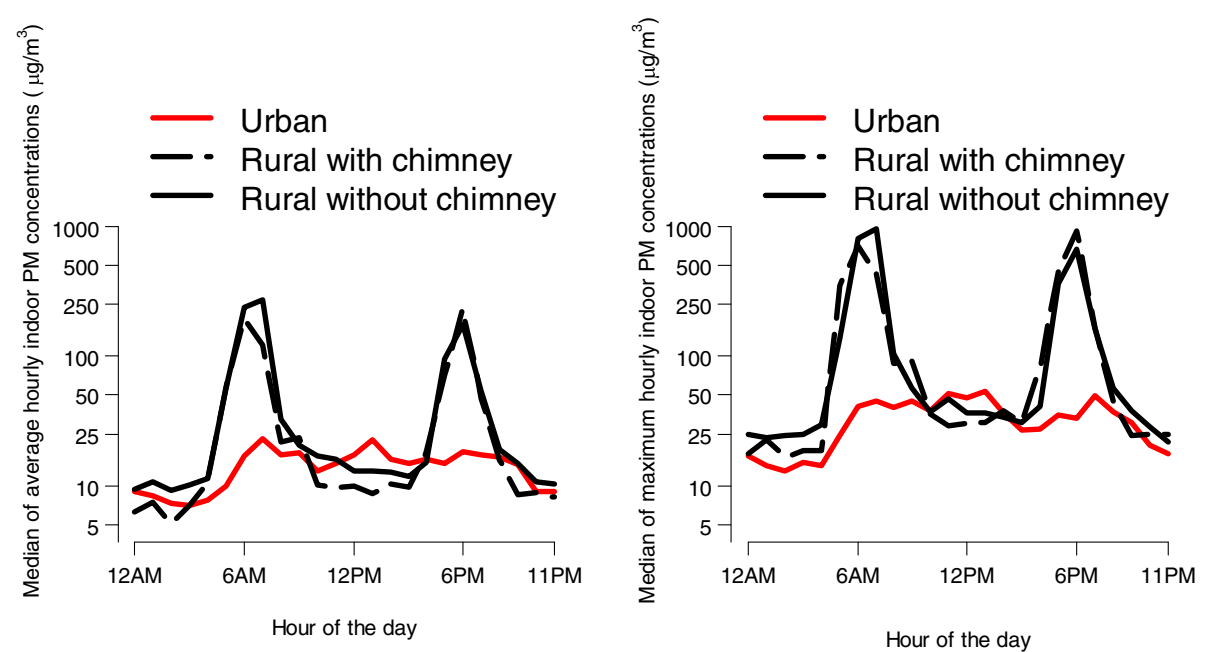

Figure 2 Median (left) and maximum (right) average concentrations of indoor PM by hour of the day. Curves are stratified by site and chimney construction (urban, rural with chimney, and rural without chimney). The $y$-axis represents summaries of average hourly concentrations (in $\mu \mathrm{g} / \mathrm{m}^{3}$ ) of indoor PM across households. We calculated these household summaries for each hour of the day, as indicated in the x-axis. 


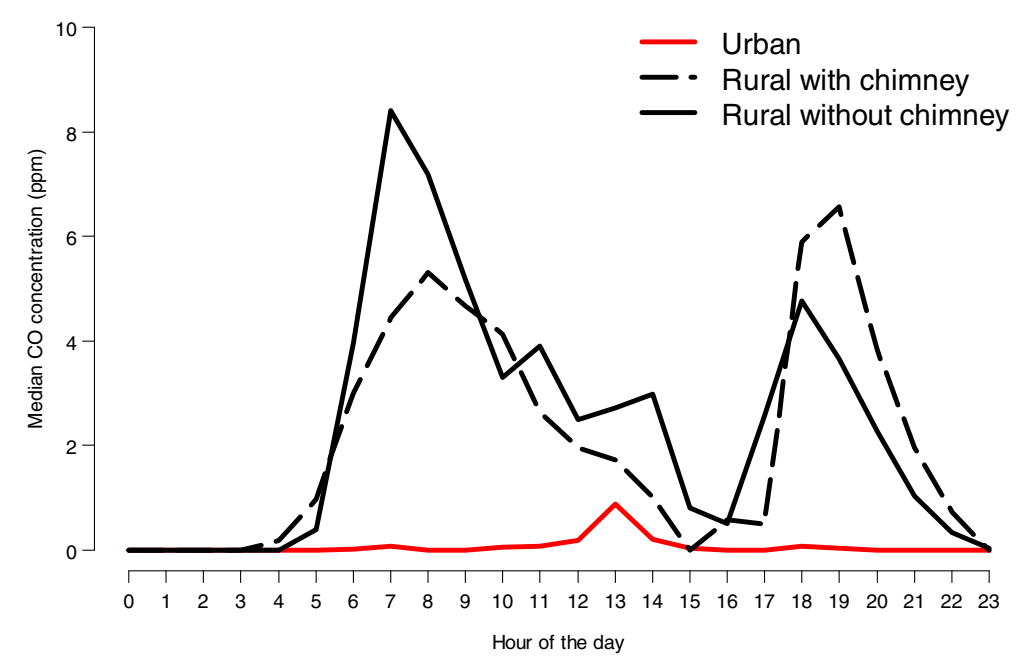

Figure 3 Median indoor CO concentrations by hour of the day. Curves are stratified by site and chimney construction (urban, rural with chimney, and rural without chimney). The $y$-axis represents median values of indoor CO (ppm) across households. We calculated these household summaries for each hour of the day, as indicated on the x-axis.

Median gravimetric 24-hour $\mathrm{PM}_{10}$ and $\mathrm{PM}_{2.5}$ concentrations were $30 \mu \mathrm{g} / \mathrm{m}^{3}$ and $13 \mu \mathrm{g} / \mathrm{m}^{3}$ for urban households, respectively, for a coarse fraction of $17 \mu \mathrm{g} / \mathrm{m}^{3}$. Median gravimetric cook time $\mathrm{PM}_{10}$ and $\mathrm{PM}_{2.5}$ concentrations in rural houses were $561 \mu \mathrm{g} / \mathrm{m}^{3}$ and $316 \mu \mathrm{g} / \mathrm{m}^{3}$, respectively, for a coarse fraction of $245 \mu \mathrm{g} / \mathrm{m}^{3}$. These data suggest that fine PM represents $43 \%$ (urban) to $56 \%$ (rural) of the exposure at our study sites.

\section{Outdoor environmental exposures}

Monthly 24-hour average $\mathrm{PM}_{2.5}$-equivalent concentrations ranged from $18 \mu \mathrm{g} / \mathrm{m}^{3}$ (March) to $29 \mu \mathrm{g} / \mathrm{m}^{3}$ (June), with an overall median of $23 \mu \mathrm{g} / \mathrm{m}^{3}$ during the study period.

\section{Factors associated with higher environmental exposures}

We identified four factors that were potentially associated with higher 24-hour average PM concentrations in multivariable analyses and after model selection using the QIC (Figure 4). Having a thatched roof ( $\mathrm{p}=0.007)$ and the number of hours cooking on a typical day (range: 1 to 6 hours per day, $\mathrm{p}=0.02$ ) were positively associated with increased 24-hour PM concentrations; however, neither having a chimney $(\mathrm{p}=0.87)$ nor using dung for cooking $(\mathrm{p}=0.17)$ were significantly associated with higher 24-hour average PM concentrations.

\section{Cardiopulmonary biomarkers associated with biomass fuel exposure}

We display results of several outcome measurements in urban vs. rural participants in Figure 5. In urban vs. rural participants: median eNO levels were $10.5 \mathrm{ppb}$ vs. $10.0 \mathrm{ppb}$ $(\mathrm{p}=0.64)$; median eCO levels were $6 \mathrm{ppm}$ vs. $9.5 \mathrm{ppm}$ $(\mathrm{p}=0.01)$; and, $\mathrm{eHbCO}$ levels were $0.96 \%$ vs. $1.56 \%(\mathrm{p}=0.04)$; median $\mathrm{SpHbCO}$ levels were $0 \%$ vs. $0 \%(\mathrm{p}=0.13)$; median $\mathrm{SpO}_{2}$ levels were $89 \%$ vs. $90 \%$ ( $\mathrm{p}=0.41$ ); and, median heart rates were 76.0 vs. 71.3 beats/minute $(\mathrm{p}=0.06)$, respectively. The Pearson correlation coefficient for eCO versus 24-hour average kitchen CO concentrations was 0.29 (95\% CI 0.07 to 0.48 ). In Table 3 , we show median values for several biomarkers in rural participants before and after cooking. eNO increased by $2 \mathrm{ppb}(\mathrm{p}=0.006)$ and $\mathrm{SpO}_{2}$ decreased by $1 \%$ $(\mathrm{p}=0.02)$ significantly after cooking; however, the magnitudes of these changes were small.

\section{Discussion}

Participants living in rural homes cooking primarily with biomass fuels experienced daily indoor PM concentrations that were 6-fold higher than participants living in the urban households in Puno. These PM exposures were up to 5.5fold higher than the 24-hour World Health Organization (WHO) safe air quality standard of $25 \mu \mathrm{g} / \mathrm{m}^{3}$ [29]. Measurements of ambient PM concentrations show that background ambient PM concentrations are not likely to contribute heavily to the exposures experienced by those cooking with biomass. There has been a growing interest in the health effects of the coarse fraction, defined as the fraction of particles between $2.5 \mu \mathrm{m}$ and $10 \mu \mathrm{m}$ in diameter [30,31]. Results of gravimetric analyses demonstrate that biomass fuel smoke had a slightly higher proportion of fine PM. In contrast, PM in urban households contain a slightly higher proportion of coarse PM, most likely contributed by ambient PM from outdoor sources. Our results are comparable to concentrations found in other studies conducted in regions where biomass fuel use is highly prevalent [32]. On average, rural participants in our study reported cooking with a traditional cookstove for 32 years, indicating that women in this region experience extremely high lifetime 

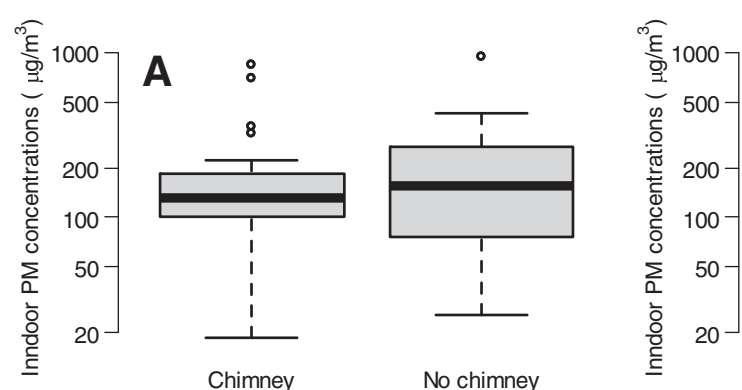

B
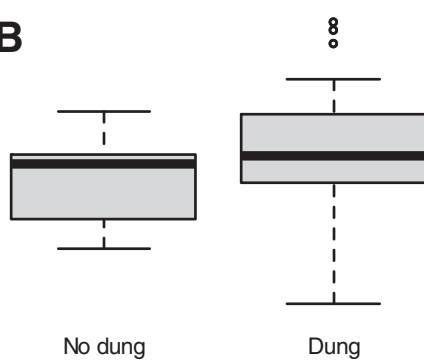

No dung
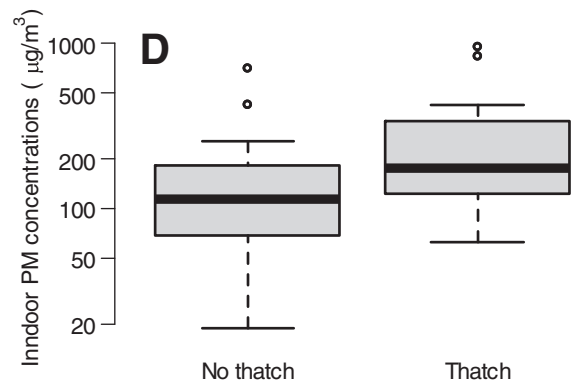

Figure 4 Boxplots of 24-hour indoor PM concentrations by household characteristics among rural participants. Presence of a chimney (panel A), use of dung while cooking (panel B), number of hours cooking (panel C), having a thatch roof (panel D).
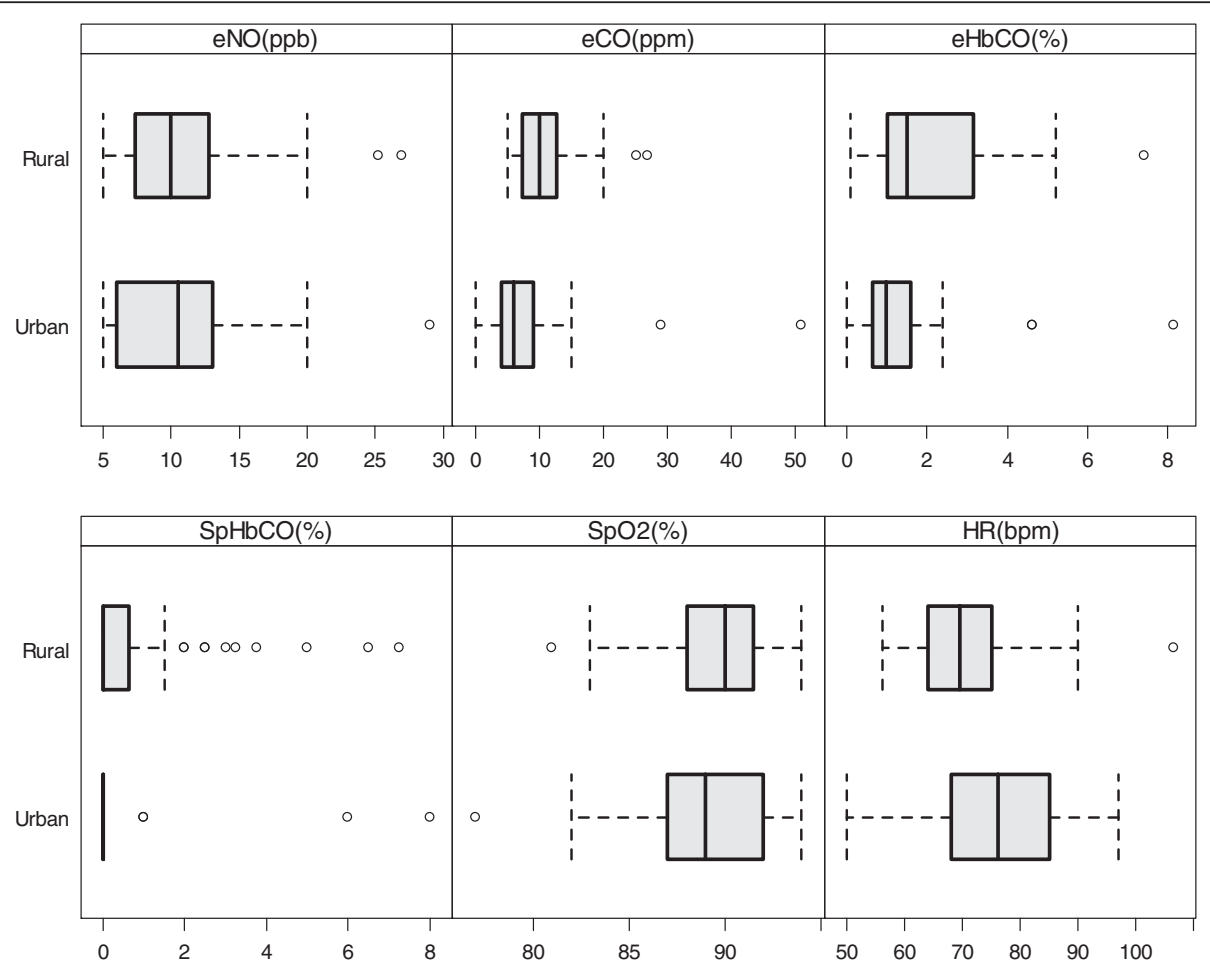

Figure 5 Boxplots of cardiopulmonary outcomes stratified by site (rural vs. urban). Displayed are exhaled nitric oxide (eNO), exhaled CO (eCO), carboxyhemoglobin from exhaled breath (eHBCO), carboxyhemoglobin from pulse co-oximetry (SpHbCO), pulse oximetry $\left(\mathrm{SpO}_{2}\right)$ and heart rate stratified by site (rural vs. urban). 
Table 3 Median values of biomarkers in rural participants before and after cooking

\begin{tabular}{llll}
\hline & Before cooking & After cooking & P-value \\
\hline eNO $(\mathrm{ppb})$ & 9 & 11 & 0.006 \\
$\mathrm{eCO}(\mathrm{ppm})$ & 9 & 10 & 0.54 \\
$\mathrm{HbCO}(\%)$ & 1.4 & 1.6 & 0.22 \\
$\mathrm{SpCO}(\%)$ & 0 & 0 & 0.25 \\
$\mathrm{SpO}_{2}(\%)$ & 90.3 & 89.3 & 0.02 \\
Heart rate & 69.5 & 71.8 & 0.12 \\
\hline
\end{tabular}

cumulative exposures to biomass smoke. Furthermore, since children are often present inside the kitchen during cooking, lifetime exposure may be even higher than our estimates, especially for women. These high cumulative exposures to biomass fuel smoke signify that individuals in this region are at elevated risk of many communicable and noncommunicable chronic diseases associated with exposure to environmental pollutants found in biomass smoke.

While PM and CO concentrations were somewhat elevated in homes without chimneys as compared to rural homes with chimneys, we did not see a significant difference in these concentrations, indicating that locally constructed chimneys were minimally effective at reducing exposures to biomass smoke in our population. Chimney design and installation varied considerably across households. Specifically, we observed chimneys that were both vertically and horizontally oriented, constructed of a variety of materials including polyvinyl chloride pipe, adobe, and brick. Some stoves were placed in a recessed area of the kitchen wall while others were not. While observing differences in exposures resulting from different forms of chimney construction is beyond the scope of this study, it is important to highlight the importance of instruction and supervision for proper construction of chimneys at the local level for future policy and implementation studies. There is a strong need to incorporate technical assistance for appropriate construction of chimney stoves in cookstove intervention programs and to evaluate the effectiveness of chimney design.

Data from our census demonstrate that at the time of our study, government-sponsored cookstove intervention programs had yet to reach many communities in the region of Puno, with only $2.4 \%$ of households reporting participation in the national improved cookstove program through JUNTOS [27]. Similarly, only five participants in our sample reported having an improved stove, and none reported having received this stove from the JUNTOS program. Only $22 \%$ of households in our census reported having chimneys in their kitchens. While it is still unclear exactly what an effective improved cookstove intervention should consist of, attention should be given to this region of Peru where there is a dire need for effective cookstove intervention programs.
We found that eNO and $\mathrm{SpO}_{2}$ changed significantly in rural participants after cooking as compared to before cooking; however, the magnitudes of these changes were negligible and not biologically meaningful. Although eCO levels were weakly but significantly correlated with 24hour $\mathrm{CO}$ concentrations, we found a significant difference in eCO levels between urban and rural participants. This reflects the differences in indoor $\mathrm{CO}$ concentrations found in urban and rural kitchens. These differences remained after eliminating the only daily smoker from the analysis. The low prevalence of current and lifetime daily smoking suggests that differences in these levels can be attributed to differences in exposure to biomass fuel smoke. While urban participants were slightly older than rural participants, we do not believe that this affected the differences in eCO levels. Other studies have also demonstrated the utility of eCO as a biomarker for biomass smoke [33,34]. However, its utility may be limited somewhat by the relatively short half-life of $\mathrm{CO}$ in the body, approximately two to 4.5 hours, depending on initial exposure [35]. In our study, since we measured eCO immediately before and after cooking in rural households, we were able to capture eCO levels within this critical window. We saw a significant difference in eCO levels between urban and rural participants, but did not observe a significant difference before as compared to after cooking. These observations suggest that eCO could represent a useful personal biomarker for longterm, chronic exposure to biomass fuel smoke. An exploration of concentrations of $\mathrm{CO}$ generated under different combustion conditions is an important validation step that would be needed to employ eCO as a marker for biomass combustion. However, in our study, biomass composition and combustion conditions were similar in all rural homes and the use of LPG was predominant in our urban homes. Therefore a discussion of the potential contributions of $\mathrm{CO}$ generated by different sources or combustion processes were beyond the scope of this analysis. eCO is simple and inexpensive to measure, requiring the participant to simply hold his or her breath for 20 seconds and then exhale fully into the machine. This simplicity is particularly useful because the instrument can be taken to the homes of the participants, instead of requiring the participant to travel to a local clinic for measurement. Hence, eCO may represent a useful and practical biomarker for biomass fuel smoke exposure and warrants further exploration for use in cookstove intervention studies.

Participants in rural areas who had a chimney installed in their homes tended to be younger than those living in homes without a chimney by about 9 years. Furthermore, rural participants who occasionally cooked LPG were younger by 9 years. While these differences may simply be a result of chance given the relatively small sample size, they also may reflect a trend for younger families to adopt these technologies. Younger 
families may also represent a willing target population for intervention.

Not surprisingly, we found that kitchen PM concentrations increased with the number of hours participants reported cooking on a typical day. In addition, although not statistically significant, we found that using dung for fuel also increased PM concentrations. We were unable to separate the effects of different types of biomass fuels (e.g. wood, dung, crop waste) on PM concentrations because most participants used multiple fuel sources for cooking. Since we excluded LPG households from the analysis, the increase in PM levels compares households that used dung with households that used other forms of biomass. Thus, our results suggest that dung use leads to a modest increase in exposure to PM even as compared to other biomass fuels. Contrary to our expectations, we found that kitchens with thatched roofs had slightly higher levels of indoor PM than other roof materials such as corrugated metal. These results could be due to the fact that thatched roofs were often tightly constructed and may have resulted in less ventilation than metal roofs. Furthermore, thatched roofs can hold a considerable amount of previously deposited PM, which can come loose when agitated or brushed by people working inside the kitchen. There has been considerable interest in the potential for using $\mathrm{CO}$ as a proxy for $\mathrm{PM}_{2.5}$ in biomass fuel studies [36]. Our results support this relationship in that kitchen $\mathrm{CO}$ concentrations were positively and significantly correlated with $\mathrm{PM}_{2.5}$ concentrations in rural households.

An important strength of our study is that two or more trained observers were present during the cooking period in rural homes, allowing us to directly record household characteristics and cooking behaviors rather than relying on self-report. There are also limitations to our study. First, concentrations measured in a household kitchen may not represent personal exposures. In particular, we may be underestimating personal exposures to environmental pollutants in urban participants given that they are likely exposed to higher concentrations of ambient PM when outside the home. Outdoor PM concentrations in rural areas are quite low, and thus kitchen exposures are likely to be the predominant source of PM exposure for rural participants. However, time spent indoors is a significant modifier of personal exposure. Second, we only recorded kitchen concentrations of household air pollution for a 24-hour period. Given the high intra-household variation found in other studies [37], longer monitoring periods would have provided more data to evaluate this variability. Third, we were unable to stay for the full duration of fuel combustion, and in most instances we were unable to determine whether participants remained in the kitchen until the fire was completely extinguished.
It is possible that participants changed their cooking behaviors as a result of our presence in their homes. Regardless, we believe that this effect was not a great source of error and we prefaced all of our visits by emphasizing that we wanted them to cook as they normally do.

Another important strength of our study is that we conducted gravimetric $\mathrm{PM}_{2.5}$ measurements concurrent with passive, real-time nephelometric measurements in order to validate and generate a calibration equation for passive measurements against a gold standard. Real-time optical devices, such as the pDR1000 used in this study, are thought to overestimate $\mathrm{PM}_{2.5}$ mass compared to gravimetric assessments [38]. We found in our study that the pDR-1000 tended to underestimate PM at very low concentrations as compared to gravimetric measurements and overestimated $\mathrm{PM}$ at higher concentrations, following a logarithmic function. There are important limitations to the validation component of our study. First, due to logistical limitations, we pre- and post-calibrated pumps in the study office, as opposed to calibrating immediately before and after deployment in the field, which may have led to variable accuracy in recorded pump flow. Second, we observed breakthrough PM on many of the filters, meaning that our calibration equation most likely yields conservative concentration estimates after correction. However, our study is valuable and novel in that it investigates the use of a real-time optical instrument (the pDR-1000) that is simple to use in a setting where it is logistically challenging to carry out the gold standard (gravimetric) measurement method.

\section{Conclusions}

Environmental exposures due to biomass fuel smoke were several-fold greater in rural vs. urban households, and having a chimney did not significantly reduce these exposures in rural households. Technical assistance for appropriate stove and chimney construction should be a key component of intervention programs. Measurement of eCO may represent a useful and easily measurable cardiopulmonary biomarker for chronic exposure to biomass fuel smoke in future studies.

\footnotetext{
Abbreviations

PM: Particulate matter; CO: Carbon monoxide; COPD: Chronic obstructive pulmonary disease; LPG: Liquid propane gas; eNO: Exhaled nitric oxide; eCO: Exhaled carbon monoxide; eHbCO: Carboxyhemoglobin measured from eCO; $\mathrm{SpO}_{2}$ : Oxygen saturation; SpHBCO: Carboxyhemoglobin measured from pulse co-oximetry; HR: Heart rate; QIC: Quasilikelihood information criterion.

\section{Competing interests}

The authors have no competing interests to declare.

Authors' contributions

SLP contributed to study design, coordinated data collection, conducted statistical analyses, and drafted the manuscript. DLW and PNB contributed to study design and drafting of the manuscript. PAB assisted in study design and data collection. LMG assisted in data collection. RHG and JJM
} 
contributed to drafting the manuscript. WC conceived of the study and contributed to study design, statistical analyses, drafting of the manuscript and had ultimate oversight over study design and administration. All authors approved the final manuscript.

\section{Acknowledgements}

We gratefully acknowledge Ms. Monica Franchy and Dr. Luz Carbajal of the Unidad de Salud Ambiental Comunitaria at the Universidad Peruana Cayetano Heredia for their assistance in conducting this study. The team also acknowledges Ms. Yasmira Carpio Toledo and Ms. Mariela Toledo Quispe for their contributions to this study.

\section{Sources of funding}

This project was funded in part by a Johns Hopkins National Institutes of Environmental Health Sciences Center for Urban Environmental Health Pilot Project (P30ES003819), and with federal funds by the National Heart, Lung and Blood Institute, United States National Institutes of Health, Department of Health and Human Services under contract number HHSN268200900033C. William Checkley was supported by a Pathway to Independence Award (ROOHL096955) from the National Heart, Lung and Blood Institute, National Institutes of Health. Suzanne Pollard was supported by a Center for Global Health Field Research Award (Johns Hopkins University) and by a grant from the Fogarty International Center, Office of AIDS Research, National Cancer Center, National Heart, Blood, and Lung Institute, and the NIH Office of Research for Women's Health through the Fogarty Global Health Fellows Program Consortium comprised of the University of North Carolina, Johns Hopkins University, Morehouse School of Medicine, and Tulane University (5R25TW009340). Publication of this article was funded in part by the Open Access Promotion Fund of the Johns Hopkins University Libraries.

\section{Other members of the CRONICAS Cohort Study group}

Antonio Bernabé-Ortiz, Juan P. Casas, George Davey Smith, Gregory B. Diette, Shah Ebrahim, Raúl Gamboa, Héctor H. García, Luis Huicho, Fabiola León-Velarde, Germán Málaga, Víctor M. Montori, María Rivera Ch. Katherine Sacksteder, Liam Smeeth; Robert A. Wise.

\section{Author details}

'Division of Pulmonary and Critical Care, School of Medicine, Johns Hopkins University, 1800 Orleans Ave, Suite 9121, Baltimore, MD, USA. ${ }^{2}$ Program in Global Disease Epidemiology and Control, Department of International Health, Johns Hopkins University, Bloomberg School of Public Health, Baltimore, MD, USA. ${ }^{3}$ Department of Environmental Health Sciences, Johns Hopkins University, Bloomberg School of Public Health, Baltimore, MD, USA. ${ }^{4}$ CRONICAS Center of Excellence in Chronic Diseases, Universidad Peruana Cayetano Heredia, Lima, Peru. ${ }^{5}$ Departamento de Medicina, Escuela de Medicina, Universidad Peruana Cayetano Heredia, Lima, Peru.

Received: 1 October 2013 Accepted: 14 March 2014

Published: 24 March 2014

\section{References}

1. Torres-Duque C, Maldonado D, Pérez-Padilla R, Ezzati M, Viegi G, Forum of International Respiratory Studies (FIRS) Task Force on Health Effects of Biomass Exposure: Biomass fuels and respiratory diseases: a review of the evidence. Proc Am Thorac Soc 2008, 5:577-590.

2. Bruce N, Perez-Padilla R, Albalak R: Indoor air pollution in developing countries: a major environmental and public health challenge. Bull World Health Organ 2000, 78:1078-1092.

3. Mathers C, Stevens G, Mascarenhas M: Global health risks: mortality and burden of disease attributable to selected major risks. Geneva: World Health Organization; 2009

4. Lim SS, Vos T, Flaxman AD, Danaei G, Shibuya K, Adair-Rohani H, Amann M, Anderson HR, Andrews KG, Aryee M, Atkinson C, Bacchus LJ, Bahalim AN, Balakrishnan K, Balmes J, Barker-Collo S, Baxter A, Bell ML, Blore JD, Blyth F, Bonner C, Borges G, Bourne R, Boussinesq M, Brauer M, Brooks P, Bruce NG, Brunekreef B, Bryan-Hancock C, Bucello C, et al: A comparative risk assessment of burden of disease and injury attributable to 67 risk factors and risk factor clusters in 21 regions, 1990-2010: a systematic analysis for the Global Burden of Disease Study 2010. Lancet 2012, 380:2224-2260.
5. Smith KR, Samet JM, Romieu I, Bruce N: Indoor air pollution in developing countries and acute lower respiratory infections in children. Thorax 2000, 55:518-532.

6. Liu Q, Sasco AJ, Riboli E, Hu MX: Indoor air pollution and lung cancer in Guangzhou, People's Republic of China. Am J Epidemiol 1993, 137:145-154.

7. Orozco-Levi M, Garcia-Aymerich J, Villar J, Ramirez-Sarmiento A, Antó JM, Gea J: Wood smoke exposure and risk of chronic obstructive pulmonary disease. Eur Respir J 2006, 27:542-546.

8. Shrestha IL, Shresta SL: Indoor air pollution from biomass fuels and respiratory health of the exposed population in Nepalese households. Int J Occup Environ Health 2005, 11:150-160.

9. Rinne ST, Rodas EJ, Bender BS, Rinne ML, Simpson JM, Galer-Unti R, Glickman LT: Relationship of pulmonary function among women and children to indoor air pollution from biomass use in rural Ecuador. Respir Med 2006, 100:1208-1215.

10. Akhtar T, Ullah Z, Khan MH, Nazli R: Chronic bronchitis in women using solid biomass fuel in rural Peshawar, Pakistan. Chest 2007, 132:1472-1475.

11. Liu S, Zhou Y, Wang X, Wang D, Lu J, Zheng J, Zhong N, Ran P: Biomass fuels are the probable risk factor for chronic obstructive pulmonary disease in rural South China. Thorax 2007, 62:889-897.

12. Perez-Padilla R, Regalado J, Vedal S, Paré P, Chapela R, Sansores R, Selman M: Exposure to biomass smoke and chronic airway disease in Mexican women. A case-control study. Am J Respir Crit Care Med 1996, 154:701-706.

13. Clark ML, Bazemore H, Reynolds SJ, Heiderscheidt JM, Conway S, Bachand AM, Volckens J, Peel JL: A baseline evaluation of traditional cook stove smoke exposures and indicators of cardiovascular and respiratory health among Nicaraguan women. Int J Occup Environ Health 2011, 17:113-121.

14. Fullerton $\mathrm{DG}$, Bruce $\mathrm{N}$, Gordon SB: Indoor air pollution from biomass fuel smoke is a major health concern in the developing world. Trans $R$ Soc Trop Med Hyg 2008, 102:843-851.

15. Nogueira JB: Air pollution and cardiovascular disease. Rev Port Cardiol 2009, 28:715-733.

16. Painschab MS, Davila-Roman VG, Gilman RH, Vasquez-Villar AD, Pollard SL, Wise RA, Miranda JJ, Checkley W: Biomass fuel smoke exposure is associated with increased carotid artery intima-media thickness and higher prevalence of atherosclerotic plaques. Heart 2013, 99:984-991.

17. Ling SH, Van Eeden SF: Particulate matter air pollution exposure: role in the development and exacerbation of chronic obstructive pulmonary disease. Int J Chron Obstruct Pulmon Dis 2009, 4:233-243.

18. Sood A: Indoor fuel exposure and the lung in both developing and developed countries. Clin Chest Med 2012, 33:649-665.

19. Ernst A, Zibrak JD: Carbon monoxide poisoning. N Engl I Med 1998, 339:1603-1608

20. Bruce EN, Bruce MC, Erupaka-Chada K: A mathematical modeling approach to risk assessment for normal and anemic women chronically exposed to carbon monoxide from biomass-fueled cookstoves. J Appl Physiol 2011, 111:473-484.

21. Park $E$, Lee $K$ : Particulate exposure and size distribution from wood burning stoves in Costa Rica. Indoor Air 2003, 13:253-259.

22. Naeher LP, Smith KR, Leaderer BP, Mage D, Grajeda R: Indoor and outdoor PM2.5 and CO in high- and low-density Guatemalan villages. J Expo Anal Environ Epidemiol 2000, 10:544-551.

23. Cynthia AA, Edwards RD, Johnson M, Zuk M, Rojas L, Jimenez RD, Riojas-Rodriguez H, Masera O: Reduction in personal exposures to particulate matter and carbon monoxide as a result of the installation of a Patsari improved cook stove in Michoacan Mexico. Indoor Air 2008, 18:93-105.

24. Edwards RD, Liu Y, He G, Yin Z, Sinton J, Peabody J, Smith KR: Household $\mathrm{CO}$ and PM measured as part of a review of China's National Improved Stove Program. Indoor Air 2007, 17:189-203.

25. Pearce JL, Aguilar-Villalobos M, Rathbun SL, Naeher LP: Residential exposures to PM2.5 and CO in Cusco, a high-altitude city in the Peruvian Andes: a pilot study. Arch Environ Occup Health 2009, 64:278-282.

26. Siddiqui AR, Lee K, Bennett D, Yang X, Brown KH, Bhutta ZA, Gold EB: Indoor carbon monoxide and PM2.5 concentrations by cooking fuels in Pakistan. Indoor Air 2009, 19:75-82.

27. Proyecto Nacional de Apoyo Directo a los Mas Pobres: JUNTOS [Internet]. Available at www.juntos.gob.pe.

28. Chakrabarti B, Fine PM, Delfino R, Sioutas C: Performance evaluation of the active-flow personal DataRAM PM2.5 mass monitor (Thermo Anderson pDR-1200) designed for continuous personal exposure measurements. Atmospheric Environment 2004, 38:3329-3340. 
29. WHO: WHO Air Quality Guidelines for particulate matter, ozone, nitrogen dioxide, and sulfur dioxide: Global update 2005. Geneva; 2006. Available from http://www.euro.who.int/_data/assets/pdf_file/0005/78638/E90038.pdf.

30. Peng RD, Chang HH, Bell ML, McDermott A, Zeger SL, Samet JM, Dominici F: Coarse particulate matter air pollution and hospital admissions for cardiovascular and respiratory diseases among Medicare patients. JAMA 2008, 299:2172-2179.

31. McCormack MC, Breysse PN, Matsui EC, Hansel NN, Williams D, CurtinBrosnan J, Eggleston P, Diette GB: In-Home Particle Concentrations and Childhood Asthma Morbidity. Environ Health Perspect 2009, 117:294-298.

32. Kurmi OP, Lam KB, Aynes JG: Indoor air pollution and the lung in lowand middle-income countries. Eur Resp J 2012, 40:239-254.

33. Diaz E, Smith-Sivertsen T, Pope D, Lie RT, Diaz A, McCracken T, Arana B, Smith KR, Bruce N: Eye discomfort, headache and back pain among Mayan Guatemalan women taking part in a randomized stove intervention trial. J Epidemiol Community Health 2007, 61:74-79.

34. Banerjee M, Siddique S, Dutta A, Mukherjee B, Ray MR: Cooking with biomass increases the risk of depression in pre-menopausal women in India. Social Sci Med 2012, 75:565-572.

35. Sandberg A, Sköld CM, Grunewald J, Eklund A, Wheelock ÅM: Assessing recent smoking status by measuring exhaled carbon monoxide levels. PLoS One 2011, 6:e28864

36. Clark ML, Peel JL, Balakrishnan K, Breysse PN, Chillrud SN, Naeher LP, Rodes CE, Vette AF, Balbus JM: Health and Household Air Pollution from Solid Fuel Use: The Need for Improved Exposure Assessment. Environ Health Perspect 2013, 121:1120-1128.

37. Smith KR, McCracken JP, Thompson L, Edwards R, Shields KN, Canuz E, Bruce N: Personal child and mother carbon monoxide exposures and kitchen levels: Methods and results from a randomized trial of woodfired chimney cookstoves in Guatemala (RESPIRE). J Expo Sci Environ Epidemiol 2010, 20:406-416.

38. Kurmi OP, Semple S, Steiner M, Henderson GD, Ayres JG: Particulate matter exposure during domestic work in Nepal. Ann Occup Hyg 2008, 52:509-517.

doi:10.1186/1476-069X-13-21

Cite this article as: Pollard et al: A cross-sectional study of determinants of indoor environmental exposures in households with and without chronic exposure to biomass fuel smoke. Environmental Health 2014 13:21.

\section{Submit your next manuscript to BioMed Central and take full advantage of:}

- Convenient online submission

- Thorough peer review

- No space constraints or color figure charges

- Immediate publication on acceptance

- Inclusion in PubMed, CAS, Scopus and Google Scholar

- Research which is freely available for redistribution 